\title{
Colonic insufflation with carbon monoxide gas inhibits the development of intestinal inflammation in rats
}

\author{
Tomohisa Takagi, Yuji Naito*, Kazuhiko Uchiyama, Toshimitsu Okuda, Takahiro Suzuki, Hisato Tsuboi, \\ Katsura Mizushima, Osamu Handa, Nobuaki Yagi, Hiroshi Ichikawa and Toshikazu Yoshikawa
}

\begin{abstract}
Background: The pathogenesis of inflammatory bowel disease (IBD) is complex, and an effective therapeutic strategy has yet to be established. Recently, carbon monoxide (CO) has been reported to be capable of reducing inflammation by multiple mechanisms. In this study, we evaluated the role of colonic CO insufflation in acute colitis induced by trinitrobenzene sulfonic acid (TNBS) in rats.

Methods: Acute colitis was induced with TNBS in male Wistar rats. Following TNBS administration, the animals were treated daily with 200 ppm of intrarectal CO gas. The distal colon was removed to evaluate various parameters of inflammation, including thiobarbituric acid (TBA)-reactive substances, tissue-associated myeloperoxidase (MPO) activity, and the expression of cytokine-induced neutrophil chemoattractant (CINC)-1 in colonic mucosa 7 days after TNBS administration.
\end{abstract}

Results: The administration of TNBS induced ulceration with surrounding edematous swelling in the colon. In rats treated with CO gas, the colonic ulcer area was smaller than that of air-treated rats 7 days after TNBS administration. The wet colon weight was significantly increased in the TNBS-induced colitis group, which was markedly abrogated by colonic insufflation with CO gas. The increase of MPO activity, TBA-reactive substances, and CINC-1 expression in colonic mucosa were also significantly inhibited by colonic insufflation with CO gas.

Conclusions: Colonic insufflation with CO gas significantly ameliorated TNBS-induced colitis in rats. Clinical application of CO gas to improve colonic inflammatory conditions such as IBD might be useful.

Keywords: Carbon monoxide (CO), Insufflation, 2,4,6-Trinitrobenzene sulfonic acid (TNBS)-induced colitis, Inflammatory bowel disease (IBD)

\section{Background}

Inflammatory bowel disease (IBD) consists of chronic and relapsing inflammatory diseases of the intestines; the pathogenesis of IBD, including Crohn's disease (CD) and ulcerative colitis (UC), is complex. Although it has been reported that genetic, immunologic, and environmental factors are involved in the initiation and perpetuation of chronic intestinal inflammation [1,2], the precise pathogenesis remains unclear. 5-aminosalicylates (5-ASA), corticosteroids, immunosuppressive agents, or

\footnotetext{
* Correspondence: ynaito@koto.kpu-m.ac.jp

Molecular Gastroenterology and Hepatology, Graduate School of Medical Science, Kyoto Prefectural University of Medicine, 465 Kajii-cho, Kawaramachi-Hirokoji, Kamigyo-ku, Kyoto 602-8566, Japan
}

anti-tumor necrosis factor (TNF)- $\alpha$ antibodies are typically used for the management of IBD. However, a substantial number of patients of IBD experience relapse or an incomplete response to these therapies.

The role of carbon monoxide (CO), a component of cigarette smoke, has been reported [3] to provide protection against chronic intestinal inflammation. Although $\mathrm{CO}$ is classified as a toxic agent that is potentially lethal and is a major pollutant in industrialized society, $\mathrm{CO}$ has recently emerged as a potent immunomodulatory entity, antiinflammatory agent, and an important factor in physiological homeostasis [4-7]. The anti-inflammatory effect of $\mathrm{CO}$ has been reported in various disease states and experimental models, including ischemia-reperfusion injury [8,9], 
organ transplantation [10], hyperoxia [11], and lipopolysaccharide (LPS)-induced sepsis [12]. In these conditions, $\mathrm{CO}$-mediated protection is associated with suppression of the inflammatory cytokine response. We have previously reported that $\mathrm{CO}$ inhalation ameliorates 2,4,6-trinitrobenzene sulfonic acid (TNBS)-induced murine colitis through TNF- $\alpha$ expression in $\mathrm{CD}^{+}{ }^{+} \mathrm{T}$ cells [13]. COreleasing molecule (CORM)-2 also suppressed colonic inflammation induced by dextran sulfate sodium (DSS) in mice [14]. In addition, $\mathrm{CO}$ inhalation suppressed inflammation in a genetically induced mouse colitis model, in interleukin (IL)-10-deficient mice [15], and in T cell receptor (TCR) $\alpha$-deficient mice [16]. Based on these reports, $\mathrm{CO}$ administration might represent a potential therapeutic strategy for IBD.

In the present study, we demonstrated the beneficial effect of $\mathrm{CO}$ in the colonic inflammatory condition by using a TNBS-induced colitis model in rats with insufflation of $\mathrm{CO}$ gas into the colonic lumen.

\section{Methods}

Animals

Male Wistar rats weighing 180-200 g were obtained from SHIMIZU Laboratory Supplies Co. Ltd. (Kyoto, Japan). The animals were housed at $22^{\circ} \mathrm{C}$ in a controlled environment with $12 \mathrm{~h}$ of artificial light per day; they were allowed access to rat chow and water ad libitum. The animals were maintained and all experimental procedures were carried out in accordance with the National Institutes of Health (NIH) guidelines for the use of experimental animals. All experimental protocols were approved by the Animal Care Committee of the Kyoto Prefectural University of Medicine (Kyoto, Japan).

\section{TNBS-induced colitis in rats}

Colitis was induced by the previously described method [17]. In brief, the rats were anesthetized with pentobarbital sodium (Kyoritsu Seiyaku Corporation, Tokyo, Japan). Following lower abdominal laparotomy, the colon was exposed. The middle portion of the colon was pinched with ring forceps (inside diameter, $8 \mathrm{~mm}$ ), and $0.2 \mathrm{~mL}$ of $30 \%$ ethanol solution containing a final concentration of 0.2 M TNBS (Sigma-Aldrich Japan, Tokyo, Japan) was injected into the luminal side of the clamped portion of the colon. After $2 \mathrm{~min}$, the colon was returned to the abdominal cavity and the incision was sutured. All procedures apart from TNBS injection were performed in rats in the sham-operated control group.

\section{Treatment protocol}

Following TNBS administration, the animals were treated daily with $200 \mathrm{ppm}$ of $\mathrm{CO}$ gas. Colonic $\mathrm{CO}$ gas insufflation (volume, $8 \mathrm{~mL}$ ) was performed using a rubber catheter (outer diameter, $2 \mathrm{~mm}$ ) via the anus under light anesthesia with diethyl ether (Wako Pure Chemicals, Osaka, Japan). The colonic insufflation with $\mathrm{CO}$ gas performed twice a day for 7 days after the induction of TNBS colitis in rats. All animals were randomized into groups treated with colonic $\mathrm{CO}$ gas insufflation or air insufflation.

The rats were sacrificed 7 days after TNBS treatment, and the distal colon was removed and opened by longitudinal incision. The wet colon weight was measured immediately thereafter. The size of the ulcer was also measured, and the ulcer index was calculated from the resultant length and width measurements $\left(\mathrm{mm}^{2}\right)$. For histologic evaluation, formalin-fixed tissues were stained with hematoxylin and eosin and evaluated by light microscopy.

\section{Measurements of thiobarbituric acid (TBA)-reactive substances and myeloperoxidase (MPO) activity}

As an index of lipid peroxidation, the total concentration of TBA-reactive substances was measured in the intestinal mucosa as previously described $[13,18]$. Briefly, the colonic mucosa was scraped off using 2 glass slides, and was then homogenized with $1.5 \mathrm{~mL}$ of $10 \mathrm{mM}$ potassium phosphate buffer ( $\mathrm{pH} 7.8)$ containing $30 \mathrm{mM} \mathrm{KCl}$. The level of TBA-reactive substances in the mucosal homogenates was expressed as nmoles of malondialdehyde/mg of protein, using 1,1,3,3-tetramethoxypropane as the standard. The total protein in the tissue homogenates was measured with a Bio-Rad Protein Assay kit (Bio-Rad Laboratories, K. K., Tokyo, Japan) according to the manufacturer's protocol.

Tissue-associated MPO activity in the intestinal mucosa was determined as an index of neutrophil accumulation as described elsewhere [13,18]. The mucosal homogenates were centrifuged at $20,000 \times g$ for $15 \mathrm{~min}$ at $4^{\circ} \mathrm{C}$ to collect the insoluble cellular debris. The resultant pellet was then homogenized in an equivalent volume of $0.05 \mathrm{M}$ potassium phosphate buffer ( $\mathrm{pH}$ 5.4) containing $0.5 \%$ hexadecyltrimethylammonium bromide. The samples were centrifuged at 20,000 $\times g$ for $15 \mathrm{~min}$ at $4^{\circ} \mathrm{C}$, and the supernatants were saved. MPO activity was assessed by measuring the $\mathrm{H}_{2} \mathrm{O}_{2}$-dependent oxidation of $3,3^{\prime}, 5,5^{\prime}$-tetramethylbenzidine. One unit of enzyme activity was defined as the amount of MPO required to cause a change in absorbance of $1.0 / \mathrm{min}$ at $645 \mathrm{~nm}$ and $25^{\circ} \mathrm{C}$.

\section{Determination of the colonic mucosal content and mRNA expression of cytokine-induced neutrophil chemoattractant (CINC)-1}

The concentration of rat CINC-1, a potent member of the IL-8 family $[19,20]$, in the colonic mucosal homogenates was determined with the Rat GRO/CINC-1 Assay kit (Immuno-Biological Laboratories Co., Ltd., Gunnma, Japan), according to the manufacturer's instructions. 
The colonic mucosal mRNA expression of CINC-1 (and $\beta$-actin as the internal control), was determined by real-time PCR according to the protocol used in our previous study $[13,14]$. Tissue samples for mRNA isolation were removed from colonic mucosa. Total RNA was isolated by the acid guanidinium-phenolchloroform method with Isogen (Nippon Gene Co. Ltd., Tokyo, Japan). The isolated RNA was stored at $-70^{\circ} \mathrm{C}$ until use in real-time PCR. For real-time PCR, $1 \mu \mathrm{g}$ of extracted RNA was reverse-transcribed into firststrand complementary DNA (cDNA) using the High Capacity cDNA Reverse Transcription Kit (Applied Biosystems, Foster City, CA, USA). Real-time PCR for CINC-1 and $\beta$-actin performed with a 7300 RealTime PCR system (Applied Biosystems) using the DNA-binding dye SYBR ${ }^{\circledR}$ Green for the detection of PCR products. The primers had the following sequences: CINC-1 sense, $5^{\prime}$-CCATTAAGTGTCAACC ACTGTGCTA-3'; CINC-1 antisense, 5'-CACATTTC CTCACCCTAACACAAA- $3^{\prime} ; \beta$-actin sense, $5^{\prime}$-GAGC AAACATCCCCCAAAGTT-3'; and; $\beta$-actin antisense, $5^{\prime}$-GCCGTGGATACTTGGAGTGACT-3'. Relative quantification of gene expression from the real-time PCR data was calculated relative to $\beta$-actin expression.

\section{Statistical analysis}

The results are presented as the mean \pm standard error of the mean (SEM). Overall differences between the groups were determined by one-way analysis of variance (ANOVA). For cases in which the one-way ANOVA was significant, differences between individual groups were analyzed by Bonferroni's multiple comparisons test. Differences in which $P<0.05$ were considered significant. All analyses were performed using the GraphPad Prism 4 program (GraphPad Software Inc., San Diego, CA, USA) for Macintosh.

\section{Results}

\section{Effect of colonic insufflation with $\mathrm{CO}$ gas on} TNBS-induced colitis

After 7 days of treatment with TNBS, macroscopic findings in the colon demonstrated severe colonic ulceration, with a marked difference in margin relative to the normal mucosa in addition to surrounding edematous swelling. In rats treated with colonic CO gas insufflation, the area of the colonic ulcer was smaller than that of air-treated rats (Figure 1A). More precisely, while the ulcer index was $68.5 \pm 3.7 \mathrm{~mm}^{2}$ in control rats, the ulcer index in rats treated with colonically insufflated $\mathrm{CO}$ gas
(A)

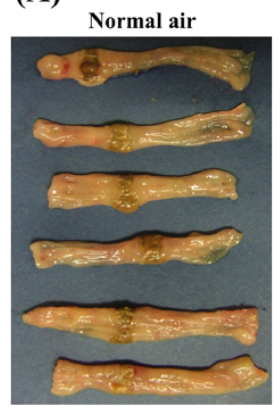

Carbon monoxide

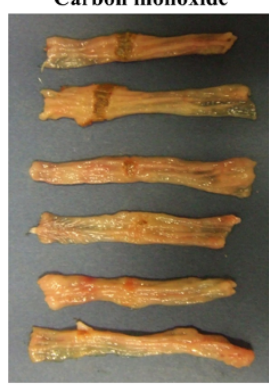

(B)

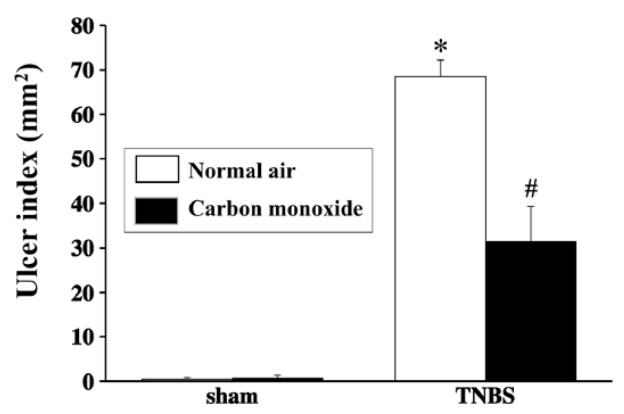

(C)

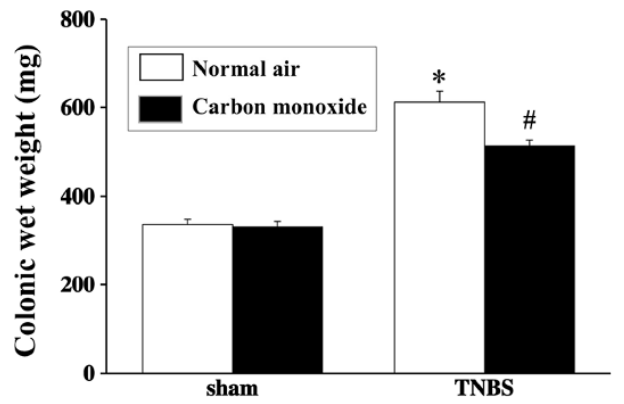

Figure 1 Effects of CO insufflation into the colonic lumen on macroscopic findings, mucosal damage score, and wet colon weight after trinitrobenzene sulfonic acid (TNBS)-induced injury. (A) Severe colitis was induced, including hyperemia, edema, thickening, ulceration, and necrosis, in TNBS-treated rats (normal air group). These changes were reduced in rats treated by CO insufflation into the colonic lumen (CO group). (B) The ulcer index was evaluated. ${ }^{*} P<0.01$ compared to sham-operated rats. ${ }^{\#} P<0.05$ compared to rats with TNBS-induced colitis receiving normal air insufflation. $(\mathbf{C})$ The wet colon weight was measured. Data represent the mean \pm SEM of 7 rats. ${ }^{*} P<0.05$ relative to shamoperated rats. ${ }^{\#} P<0.05$ relative to rats with TNBS-induced colitis receiving normal air insufflation. 
was $31.3 \pm 7.9 \mathrm{~mm}^{2}$ (Figure 1B). Furthermore, the wet colon weight was significantly increased in the TNBS colitis group (air-treated rats). This increase was significantly ameliorated by treatment with colonically insufflated $\mathrm{CO}$ gas (Figure 1C).

The effects of treatment with the colonically insufflated $\mathrm{CO}$ gas were also confirmed by histological examination. Figure 2 shows the representative histological features of a normal colon in sham-operated rats (A), those of TNBS-induced colitis group (treated with air, B) and those of the $\mathrm{CO}$ gas-treated group $(\mathrm{C})$. The administration of TNBS induced a marked thickening of the colonic wall and large colonic ulceration with transmural infiltration of numerous inflammatory cells (Figure 2B), as compared to the normal colon (Figure 2A). However, in rats treated with $\mathrm{CO}$ gas, an inhibition of both mural wall thickening and colonic ulceration was observed (Figure 2C).

\section{Effect of colonic insufflation with CO gas on TBA-reactive substances and MPO activity}

The extent of lipid peroxidation was determined by measuring the TBA-reactive substances present in the colonic mucosa. In the sham-operated group, there were no differences in the levels of intestinal TBA-reactive substances between $\mathrm{CO}$ gas- and normal air-treated rats. However, the TNBS-induced colitis caused a significant increase in TBA-reactive substances compared to that of the sham-operated rats. The increase in TBA-reactive substances in the colonic mucosa was significantly inhibited by colonic insufflation with CO gas (Figure 3A).

Neutrophil accumulation was also evaluated by the measurement of tissue-associated MPO activity in colonic mucosal homogenates. In the sham-operated animals, there were no differences in the MPO activities between $\mathrm{CO}$ gas- and normal air-treated rats. In contrast,
MPO activity in the colonic mucosa was markedly increased in animals with TNBS-induced colitis relative to that of the sham-operated group. The MPO activity in the colonic mucosa after the induction of colitis with TNBS was significantly inhibited by treatment with colonic $\mathrm{CO}$ gas insufflation (Figure $3 \mathrm{~B}$ ).

\section{Effect of colonic insufflation with CO gas on CINC-1 protein and mRNA expression in the colonic mucosa}

To further analyze the effects of the colonic insufflation with $\mathrm{CO}$ gas on neutrophil accumulation in the colonic mucosa, we assessed the colonic mucosal CINC-1 protein level using an enzyme-linked immunosorbent assay (ELISA) and CINC-1 mRNA expression using real time-PCR. The colonic CINC-1 protein level increased significantly after the induction of colitis with TNBS. The increase in CINC-1 in the colonic mucosa was significantly inhibited by colonic insufflation with $\mathrm{CO}$ gas (Figure 4A). RNA extracts obtained from the colon were subjected to real-time PCR to measure CINC-1 gene expression. As shown in Figure 4B, subtle expression of the CINC-1 gene was revealed in sham-operated rats, while $C I N C-1$ transcription was enhanced in the TNBS-treated rats. Treatment with $\mathrm{CO}$ gas suppressed CINC-1 mRNA expression in the inflamed colonic tissue (Figure $4 \mathrm{~B}$ ).

\section{Discussion}

In the present study, we demonstrated that insufflation of $\mathrm{CO}$ gas into the colonic lumen decreased colonic mucosal damage and inflammation induced by TNBS. To our knowledge, this is the first report demonstrating the anti-inflammatory effect of insufflation of $\mathrm{CO}$ gas into the colonic lumen. The pathogenesis of IBD such as CD and UC are complicated and remain unclear. Concurrently, although new treatment modalities such as

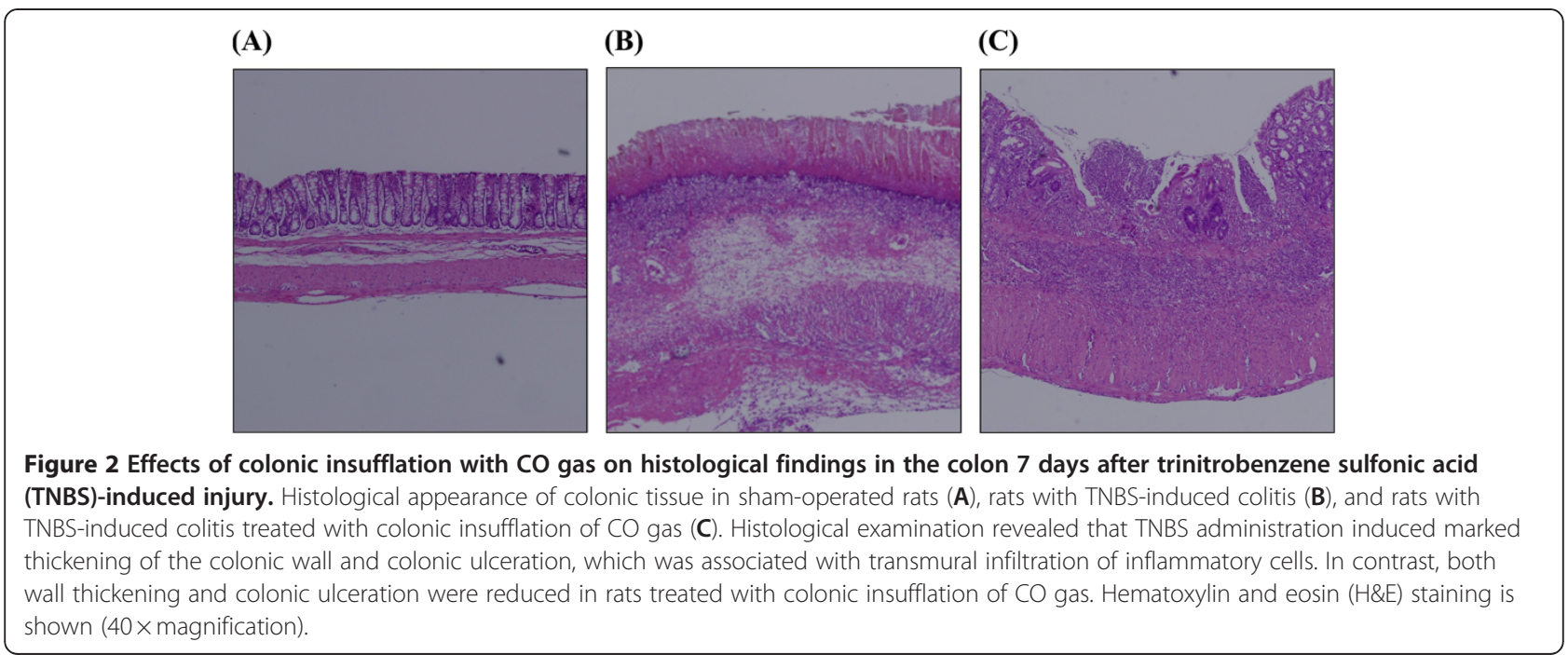


(A)

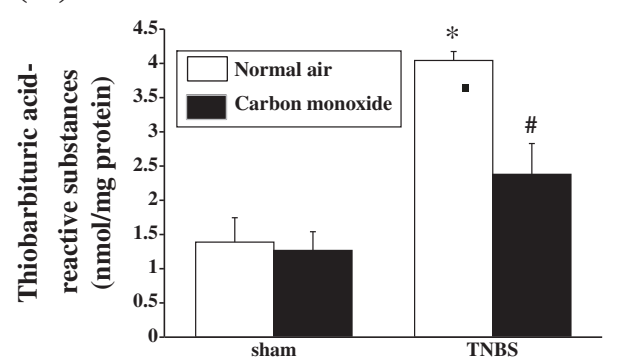

(B)

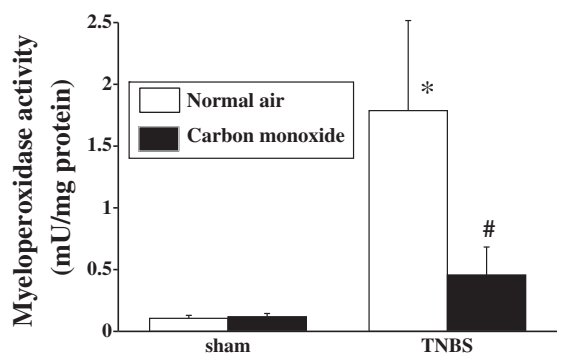

Figure 3 Effects of $\mathrm{CO}$ insufflation into the colonic lumen on thiobarbituric acid (TBA)-reactive substances and tissue-associated myeloperoxidase (MPO) activity. The level of TBA-reactive substances (A) and MPO activity (B) were significantly inhibited in rats treated with $\mathrm{CO}$ gas insufflation. Data represent the mean \pm SEM of 7 rats. ${ }^{*} P<0.05$ relative to sham-operated rats. ${ }^{\#} P<0.05$ relative to rats with TNBS-induced colitis receiving normal air insufflation.

immunosuppressants and anti-TNF- $\alpha$ antibodies have been proposed for the treatment of IBD, the progress of disease remains poorly controlled in some patients. We suggest the possibility of the clinical application of $\mathrm{CO}$ gas to control IBD.

Cigarette smoking has been reported to have a protective effect against the development of UC $[21,22]$. Although the detailed mechanisms remain unclear, $\mathrm{CO}-\mathrm{a}$ component of cigarette smoke-has been reported to abrogate colonic inflammation. The ability of $\mathrm{CO}$ to inhibit colonic mucosal inflammation has been reported in an experimental colitis model. IL-10-deficient (IL-10 ${ }^{-/-}$) mice develop chronic colitis, which is mediated by $\mathrm{T}$ helper (Th)-1 cytokines. $\mathrm{CO}$ exposure at a concentration of $250 \mathrm{ppm}$ for 7 days ameliorated colitis in $\mathrm{IL}-10^{-/-}$ mice [15]. In Th-1 mediated inflammation, $\mathrm{CO}$ decreases the synergistic effect of interferon (IFN)- $\gamma$ on LPS-induced IL-12 p40 in murine macrophages. In addition, $\mathrm{CO}$ exposure has been reported to alleviate chronic colitis in $\mathrm{TCR}^{-1-}$ mice in which the disease is mediated by Th- 2 cytokines [16]. CO exposure at a concentration of $250 \mathrm{ppm}$ for 7 days decreased the colitis score and inflammatory cytokine expression in the colonic mucosa. In that model, $\mathrm{CO}$ induced heme oxygenase (HO)-1 expression that was correlated with increased IL-10 and IL-22 expression in macrophages, suggesting that $\mathrm{HO}-1$ induction by $\mathrm{CO}$ may be associated with anti-inflammatory mechanisms. In our previous study, TNBS-induced murine colitis was also improved by $\mathrm{CO}$ inhalation [13]. CO inhalation significantly decreased the macroscopic colonic damage score, amount of TBA-reactive substances, and MPO activity in the colonic mucosa. Not only the expression of TNF- $\alpha$ in the colonic mucosa, but also TNF- $\alpha$ production by $\mathrm{CD} 4^{+} \mathrm{T}$ cells isolated from the spleen was significantly inhibited by treatment with inhaled CO. Furthermore, CORM-2 improved colonic mucosal inflammation and damage in an experimental colitis model as well [14]. The disease activity index (DAI) score and MPO activity in the colonic mucosa were significantly decreased by treatment with CORM-2 in an acute mouse colitis model induced by DSS. The expression of inflammatory

\section{(A)}

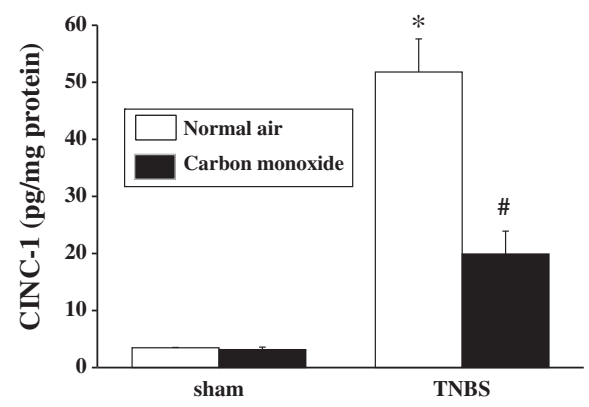

(B)

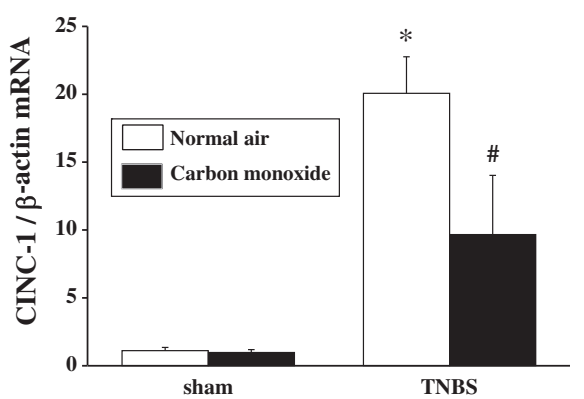

Figure 4 Effects of $\mathbf{C O}$ insufflation into the colonic lumen on CINC-1 expression. The CINC-1 protein expression level (A) and mRNA level (B) were significantly inhibited in rats treated with CO gas insufflation. Data represent the mean \pm SEM of 7 rats. ${ }^{*} P<0.01$ relative to sham-operated rats. ${ }^{\#} P<0.05$ relative to rats with TNBS-induced colitis receiving normal air insufflation. 
cytokines such as TNF- $\alpha$ and chemokines such as keratinocyte chemoattractant (KC) were decreased after CORM-2 treatment.

In the present study, we administered $\mathrm{CO}$ into the colonic lumen of rats, and $\mathrm{CO}$ insufflation significantly improved the ulcer index and decreased wet colon weight in a TNBS-induced colitis model. The level of TBA-reactive substances and MPO activity were also decreased after CO insufflation. The elevation of TBAreactive substances is a reliable indicator of lipid peroxidation, which is closely associated with tissue damage [23]. Since oxidative stress in the colonic mucosa is closely related to neutrophil infiltration, the elevation of TBA-reactive substances is suggested to be a subsequent event of the elevation of MPO activity. These results indicate that $\mathrm{CO}$ insufflation decreased neutrophil infiltration and subsequent mucosal damage. In addition, we confirmed that the induction of CINC-1 in the colonic mucosa by TNBS was significantly inhibited by $\mathrm{CO}$ treatment. CINC-1 is a homolog of human IL- 8 and plays an important role in the acute phase of inflammation $[24,25]$. Although further study is necessary to elucidate the detail mechanism by which $\mathrm{CO}$ suppresses CINC-1 expression in the colonic mucosa, it is clear that $\mathrm{CO}$ insufflation significantly reduced the expression of inflammatory mediator $\mathrm{CINC}-1$, which might result in reduced mucosal inflammation.

More importantly, blood $\mathrm{CO}$ concentration was not elevated after $\mathrm{CO}$ insufflation in the colonic lumen in this study (data not shown), indicating that the rectal administration of $\mathrm{CO}$ gas might be safety and realistic route for clinical application though the inhalation of $\mathrm{CO}$ gas caused the high toxicity through the high concentration of $\mathrm{CO}$ in blood. In addition, the unchanging $\mathrm{CO}$ concentration in blood after the rectal administration of $\mathrm{CO}$ gas may indicate that $\mathrm{CO}$ act topically in colonic mucosa. In previous study using murine colonic epithelial cells, we demonstrated that $\mathrm{CO}$ inhibited the production of keratinocyte chemoattractant (KC), which has represented a closely related chemokine involved in neutrophil recruitment [26] and been regarded as a functional homologue of IL-8, through the inhibition of NF- $\kappa B$ activation [14]. Similar to these results, Megias et al. also described that $\mathrm{CO}$ inhibited IL-8 production in a human colonic epithelial cell line, Caco-2, through the inhibition of NF- $\mathrm{KB}$ activation [27]. In view of the results from these recent investigations, the inhibition of cytokine production might be an essential mechanism by which $\mathrm{CO}$ yields anti-inflammatory effects.

For the management of IBD, since mucosal healing is associated with a better outcome with decreased risk of relapse and major surgery, direct assessment of severity and mucosal healing using endoscopy is critical $[28,29]$. In particular, for combination therapy with infliximab and azathioprine in $\mathrm{CD}$ patients, endoscopy may help to identify patients who will experience the best outcome due to early intervention [30]. However, an association between colonoscopy preparation and toxic megacolon in severe UC has been suggested [31]. It has also been reported that left-sided colonic mucosal ulcerations might be induced by sodium phosphate preparation and polyethyleneglycol $[32,33]$. Although the precise etiology of this association is unknown, an increase in crypt cell apoptosis has been suggested to be an important mechanism of mucosal damage due to colonoscopy preparation [34]. An association between colonoscopy and exacerbation of UC symptoms has been also reported [35]. As a constant air supply during the endoscopic examination is indispensable for observing the colonic mucosa, we suggest that $\mathrm{CO}$ insufflation used instead of the normal air supply during endoscopic examination of IBD patients might prevent colonic mucosal damage induced by the preparation for colonoscopy.

\section{Conclusions}

In conclusion, we demonstrated the beneficial effect of $\mathrm{CO}$ insufflation into the colonic lumen to decrease mucosal inflammation. Although additional research is required before $\mathrm{CO}$ gas can be used for clinical applications, it might be a useful new complementary therapeutic strategy for the management of IBD.

\section{Abbreviations}

IBD: Inflammatory bowel disease; CD: Crohn's disease; UC: Ulcerative colitis; 5-ASA: 5-Aminosalicylates; TNF: Tumor necrosis factor; CO: Carbon monoxide; LPS: Lipopolysaccharide; TNBS: 2,4,6-Trinitrobenzene sulfonic acid; CORM: COreleasing molecule; DSS: Dextran sulfate sodium; IL: Interleukin; TCR: T cell receptor; TBA: Thiobarbituric acid; MPO: Myeloperoxidase; CINC: Cytokineinduced neutrophil chemoattractant; SEM: Standard error of the mean; ANOVA: Analysis of variance; ELISA: Enzyme-linked immunosorbent assay; IFN: Interferon; HO: Heme oxygenase; DAl: Disease activity index; $\mathrm{KC}$ : Keratinocyte chemoattractant.

\section{Competing interests}

Yuji Naito received scholarship funds from Otsuka Pharmaceutical Co., Ltd and Takeda Pharmaceutical Co., Ltd.

Nobuaki Yagi has an affiliation with a donation-funded department from AstraZeneca Co., Ltd., Eisai Co., Ltd., Otsuka Pharmaceutical Co., Ltd., MSD K. K., Dainippon Sumitomo Pharma Co., Ltd., Chugai Pharmaceutical Co., Ltd., FUJIFILM Medical Co., Ltd. and Merck Serono Co., Ltd.

The other authors declare that there are no competing interests.

\section{Authors' contributions}

$\Pi \mathrm{T}, \mathrm{TO}, \mathrm{TS}$, and $\mathrm{HT}$ performed rat experiments. $\Pi \mathrm{T}$ and $\mathrm{YN}$ participated in the design of the study. $\mathrm{KM}$ and $\mathrm{OH}$ performed the gene expression analysis. NY performed the measurement of biochemical index such as MPO activity. HI performed the statistical analysis. KU helped to draft the manuscript. TY provided overall supervision. All authors read and approved the final manuscript

\section{Acknowledgments}

This work was supported by Grants-in-Aid for Scientific Research (C) to Y.N. (no. 22590705) and (C) to T.T. (no. 22590706) from the Japan Society for the Promotion of Science, and by an Adaptable and Seamless Technology Transfer Program through target-driven R\&D to Y.N. from the Japan Science and Technology Agency. 
Received: 29 August 2012 Accepted: 29 August 2012

Published: 3 September 2012

\section{References}

1. Elson CO, Sartor RB, Targan SR, Sandborn WJ: Challenges in IBD research: Updating the scientific agendas. Inflamm Bowel Dis 2003, 9:137-153.

2. Plevy S, Mayer L: Meeting summary: Signal transduction pathways in immune and inflammatory cells. November 30-December 3, 2000, Amelia Island, Florida, U.S.A. Inflamm Bowel Dis 2003, 9:28-33.

3. Sawano M, Shimouchi $A$ : A tracer analysis study on the redistribution and oxidization of endogenous carbon monoxide in the human body. J Clin Biochem Nutr 2010, 47:107-110

4. Yamamoto T, Takano N, Ishiwata K, Suematsu M: Carbon monoxide stimulates global protein methylation via its inhibitory action on cystathionine beta-synthase. J Clin Biochem Nutr 2011, 48:96-100.

5. Naito Y, Takagi T, Uchiyama K, Yoshikawa T: Heme oxygenase-1: a novel therapeutic target for gastrointestinal diseases. J Clin Biochem Nutr 2011 48:126-133.

6. Kajimura M, Fukuda R, Bateman RM, Yamamoto T, Suematsu M: Interactions of multiple gas-transducing systems: hallmarks and uncertainties of $\mathrm{CO}$, NO, and H2S gas biology. Antioxid Redox Signal 2010, 13:157-192.

7. Takano N, Yamamoto T, Adachi T, Suematsu M: Assessing a shift of glucose biotransformation by lc-ms/ms-based metabolome analysis in carbon monoxide-exposed cells. Adv Exp Med Biol 2010, 662:101-107.

8. Kaizu T, Nakao A, Tsung A, Toyokawa H, Sahai R, Geller DA, Murase N: Carbon monoxide inhalation ameliorates cold ischemia/reperfusion injury after rat liver transplantation. Surgery 2005, 138:229-235.

9. Nakao A, Kimizuka K, Stolz DB, Neto JS, Kaizu T, Choi AM, Uchiyama T, Zuckerbraun BS, Nalesnik MA, Otterbein LE, Murase N: Carbon monoxide inhalation protects rat intestinal grafts from ischemia/reperfusion injury. Am J Pathol 2003, 163:1587-1598.

10. Nakao A, Toyokawa H, Abe M, Kiyomoto T, Nakahira K, Choi AM, Nalesnik MA, Thomson AW, Murase N: Heart allograft protection with low-dose carbon monoxide inhalation: effects on inflammatory mediators and alloreactive T-cell responses. Transplantation 2006, 81:220-230.

11. Otterbein LE, Mantell LL, Choi AM: Carbon monoxide provides protection against hyperoxic lung injury. Am J Physiol 1999, 276:L688-L694.

12. Otterbein LE, Bach FH, Alam J, Soares M, Tao Lu H, Wysk M, Davis RJ, Flavel RA, Choi AM: Carbon monoxide has anti-inflammatory effects involving the mitogen-activated protein kinase pathway. Nat Med 2000, 6:422-428

13. Takagi T, Naito Y, Mizushima K, Akagiri S, Suzuki T, Hirata I, Omatsu T, Handa $\mathrm{O}$, Kokura S, Ichikawa H, Yoshikawa T: Inhalation of carbon monoxide ameliorates TNBS-induced colitis in mice through the inhibition of TNF-alpha expression. Dig Dis Sci 2010, 55:2797-2804.

14. Takagi T, Naito Y, Uchiyama K, Suzuki T, Hirata I, Mizushima K, Tsuboi H, Hayashi N, Handa O, Ishikawa T, Yagi N, Kokura S, Ichikawa H, Yoshikawa T: Carbon monoxide liberated from carbon monoxide-releasing molecule exerts an anti-inflammatory effect on dextran sulfate sodium-induced colitis in mice. Dig Dis Sci 2011, 56:1663-1671.

15. Hegazi RA, Rao KN, Mayle A, Sepulveda AR, Otterbein LE, Plevy SE: Carbon monoxide ameliorates chronic murine colitis through a heme oxygenase 1-dependent pathway. J Exp Med 2005, 202:1703-1713.

16. Sheikh SZ, Hegazi RA, Kobayashi T, Onyiah JC, Russo SM, Matsuoka K, Sepulveda AR, Li F, Otterbein LE, Plevy SE: An anti-inflammatory role for carbon monoxide and heme oxygenase-1 in chronic th2-mediated murine colitis. J Immunol 2011, 186:5506-5513.

17. Uchida M, Mogami O: Milk whey culture with propionibacterium freudenreichii ET-3 is effective on the colitis induced by $2,4,6$ trinitrobenzene sulfonic acid in rats. J Pharmacol Sci 2005, 99:329-334.

18. Takagi T, Yoshida N, Isozaki Y, Shimozawa M, Katada K, Manabe H, Hanada O, Kokura S, Ichikawa H, Naito Y, Okanoue T, Yoshikawa T: CV-11974, angiotensin II type I receptor antagonist, protects against ischemia-reperfusion injury of the small intestine in rats. Eur J Pharmacol 2006, 535:283-290.

19. Takaishi K, Ohtsuka T, Tsuneyoshi S, Maehara N, Harada M, Yoshida H, Watanabe K, Tsurufuji S: Inhibition of the production of rat cytokine-induced neutrophil chemoattractant (CINC)-1, a member of the interleukin-8 family, by adenovirus-mediated overexpression of IkappaBalpha. J Biochem 2000, 127:511-516.

20. Tomatsuri N, Yoshida N, Takagi T, Katada K, Isozaki Y, Imamoto E, Uchiyama K, Kokura S, Ichikawa H, Naito Y, Okanoue T, Yoshikawa T: Edaravone, a newly developed radical scavenger, protects against ischemiareperfusion injury of the small intestine in rats. Int Journal Mol Med 2004 13:105-109.

21. Jick H, Walker AM: Cigarette smoking and ulcerative colitis. N Engl J Med 1983, 308:261-263.

22. Boyko EJ, Koepsell TD, Perera DR, Inui TS: Risk of ulcerative colitis among former and current cigarette smokers. N Engl J Med 1987, 316:707-710.

23. Lambert JD, Kennett MJ, Sang S, Reuhl KR, Ju J, Yang CS: Hepatotoxicity of high oral dose (-)-epigallocatechin-3-gallate in mice. Food Chem Toxicol 2010, 48:409-416.

24. Watanabe K, Koizumi F, Kurashige Y, Tsurufuji S, Nakagawa H: Rat CINC, a member of the interleukin-8 family, is a neutrophil-specific chemoattractant in vivo. Exp Mol Pathol 1991, 55:30-37.

25. Watanabe K, Konishi K, Fujioka M, Kinoshita S, Nakagawa H: The neutrophil chemoattractant produced by the rat kidney epithelioid cell line NRK$52 \mathrm{E}$ is a protein related to the KC/GRO protein. J Biol Chem 1989, 264:19559-19563.

26. Zlotnik A, Yoshie O: Chemokines: A new classification system and their role in immunity. Immunity 2000, 12:121-127.

27. Megias J, Busserolles J, Alcaraz MJ: The carbon monoxide-releasing molecule corm-2 inhibits the inflammatory response induced by cytokines in caco-2 cells. Br J Pharmacol 2007, 150:977-986.

28. Allez M, Lemann M: Role of endoscopy in predicting the disease course in inflammatory bowel disease. World J Gastroenterol 2010, 16:2626-2632.

29. van Assche G, Vermeire S, Rutgeerts P: Mucosal healing and anti-TNFs in IBD. Curr Drug Targets 2010, 11:227-233.

30. Colombel JF, Sandborn WJ, Reinisch W, Mantzaris GJ, Kornbluth A, Rachmilewitz D, Lichtiger S, D'Haens G, Diamond RH, Broussard DL, Tang KL, van der Woude CJ, Rutgeerts P: Infliximab, azathioprine, or combination therapy for Crohn's disease. N Engl J Med 2010, 362:1383-1395.

31. Present DH: Toxic megacolon. Medical Clin North Am 1993, 77:1129-1148.

32. Atkinson RJ, Save V, Hunter JO: Colonic ulceration after sodium phosphate bowel preparation. American J Gastroenterol 2005, 100:2603-2605.

33. Watts DA, Lessells AM, Penman ID, Ghosh S: Endoscopic and histologic features of sodium phosphate bowel preparation-induced colonic ulceration: case report and review. Gastrointest Endosc 2002, 55:584-587.

34. Driman DK, Preiksaitis HG: Colorectal inflammation and increased cell proliferation associated with oral sodium phosphate bowel preparation solution. Hum Pathol 1998, 29:972-978.

35. Menees S, Higgins P, Korsnes S, Elta G: Does colonoscopy cause increased ulcerative colitis symptoms? Inflamm Bowel Dis 2007, 13:12-18.

doi:10.1186/2045-9912-2-23

Cite this article as: Takagi et al:: Colonic insufflation with carbon monoxide gas inhibits the development of intestinal inflammation in rats. Medical Gas Research 2012 2:23.

\section{Submit your next manuscript to BioMed Central and take full advantage of:}

- Convenient online submission

- Thorough peer review

- No space constraints or color figure charges

- Immediate publication on acceptance

- Inclusion in PubMed, CAS, Scopus and Google Scholar

- Research which is freely available for redistribution 